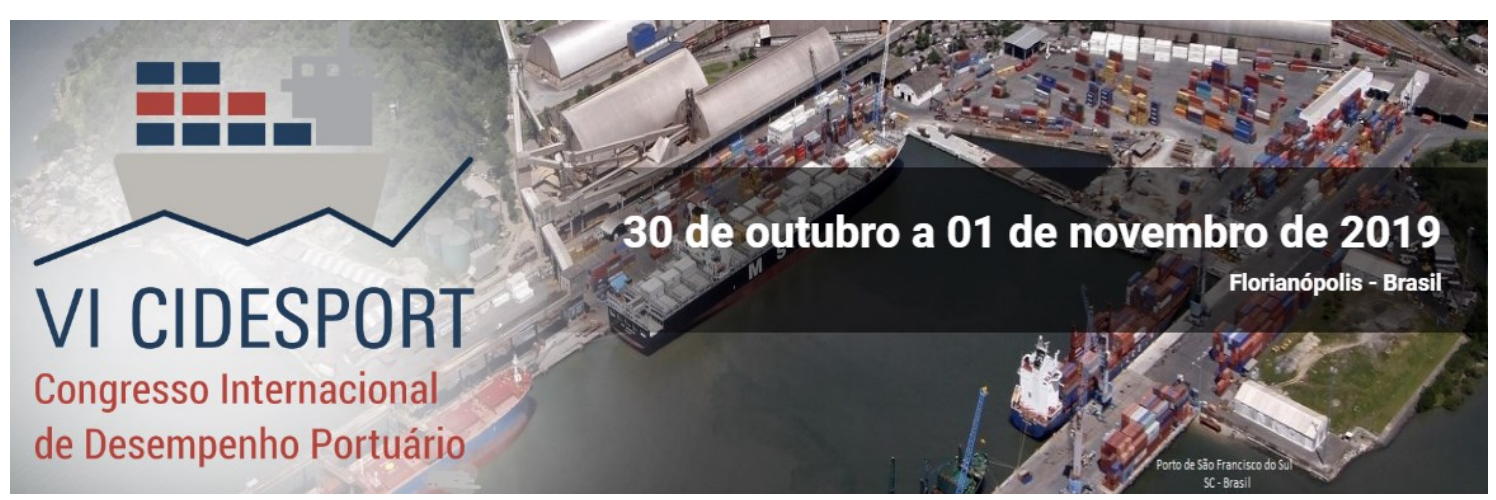

\title{
O PORTO COMO INTEGRANTE DA CADEIA LOGÍSTICO-PORTUÁRIA DE PRODUTOS REFRIGERADOS E/OU CONGELADOS: UM ESTUDO DE CASO EM SC
}

Evandro Moritz Luz Universidade Federal de Santa Catarina

\author{
Carlos Manuel Taboada Rodriguez \\ Universidade Federal de Santa Catarina
}

\begin{abstract}
Resumo: O objetivo deste trabalho é identificar o porto como um integrante de uma cadeia logístico-portuária de produtos refrigerados e/ou congelados no Estado de Santa Catarina. Justifica-se este trabalho em função do papel da contribuição dos portos na cadeia global de suprimentos que é cada vez mais estratégico para o aumento da integração, e da eficiência dos canais de distribuição de exportação. Desta forma buscou-se identificar as principais macros etapas da dependência portuária e do próprio porto, considerando o contexto de uma cadeia de exportação de produtos refrigerados e/ou congelados. Utilizou-se como metodologia um estudo de caso aplicado em SC, e como técnica de pesquisa a utilização de um questionário para legitimizar a proposta de reconhecer na cadeia o porto como um integrante, de acordo com a pesquisa bibliográfica pertinente ao tema, com experts no setor da cadeia logístico-portuária de produtos refrigerados e/ou congelados. Os objetivos propostos foram alcançados ao se estabelecer a construção por intermédio de uma sustentação teórica e legitimada com experts do mercado profissional, da formação de uma cadeia logístico-portuária em um cenário com informações de um caso em $\mathrm{SC}$, reconhecendo o porto como um elemento integrante desta cadeia.
\end{abstract}

Palavras-chave: 1. cadeia 2. logístico 3. portuária

\section{INTRODUÇÃO}

Com a globalização da economia, uma das maiores mudanças que as organizações enfrentam é a produção e entrega de bens/serviços em grandes quantidades e de baixo custo (BUCKLEY; GHAURI 2004; FAWCETT; CLOSS 1993; MUSSA, 2003), com a logística representando um suporte crítico para as organizações, pois Bagghi e Virum (1998) defendem essa posição ao afirmar que à medida que a concorrência se intensifica, as decisões tornam-se mais globalizadas e a logística torna-se uma área estratégica cada vez mais importante e uma fonte de vantagem competitiva. A utilização intensiva de conteineres, a intermodalidade, a manutenção da informação e da comunicação aumentaram de forma global, e as ligações logísticas funcionais entre os portos marítimos permitem-lhes ganhar importantes vantagens competitivas (CRUZ et al., 2013).

* A revisão gramatical, ortográfica, ABNT ou APA foi realizada pelos autores. 
Os portos marítimos são um elemento crucial no comércio marítimo, uma vez que proporcionam uma interface entre o transporte marítimo e terrestre e, portanto, uma porta de entrada para importações e exportações de um país ou região (CRUZ et al., 2013; CLARK et al., 2004). De acordo com Magala e Sammons (2008), os expedidores escolhem um porto marítimo que está inserido em um caminho logístico que minimiza os custos logísticos totais. A UNCTAD (2017) projeta a médio prazo que o comércio marítimo mundial tenha volumes crescentes anuais na estimativa de $3,2 \%$ entre 2017 e 2022, e a exigência de portos com desempenho eficiente também traz a necessidade de melhoria da conectividade marítima com o seu entorno portuário e os demais agentes intervernientes que se conectam em uma cadeia logística portuária.

É inegável o peso do transporte marítimo em comparação aos outros transportes na logística internacional. No Brasil a proporção é de $95 \%$ das mercadorias, em peso, e $90 \%$ em valor, que são comercializadas com o exterior via modal marítimo (KEEDI, 2011).

Em 2017 o Estado de Santa Catarina exportou cerca de 11 trilhões de dólares americanos, um número expressivo, diante de um valor aproximado de 217,5 trilhões de dólares americanos exportados pelo país de todos os tipos de produtos, na qual o Estado de Santa Catarina se posicionou na oitava posição entre os Estados brasileiros (COMEXSTAT, 2018).

Dos 11 trilhões exportados pelo Estado, cerca de 3,7 trilhões são de produtos refrigerados e/ou congelados, como carne e miudezas comestíveis, representando cerca de $34 \%$ (por cento) do total, e transportados via marítima por contêineres.

Os portos marítimos são considerados uma parte importante das cadeias de fornecimento internacionais (THOMAS, 2001; SLACK; FRÉMONT, 2005). Vários trabalhos reconheceram o importante papel dos portos e terminais de contêiner no contexto da gestão da cadeia de suprimentos (HEAVER, 2002; ROBINSON, 2002; CARBONE; DE MARTINO, 2003; PAIXÃO; MARLOW, 2003; BICHOU; GRAY, 2005; TONGZON; HENG, 2005; PANAYIDES, 2006; ROBINSON, 2006; WANG; CULLINANE, 2006). Para cumprir esse papel, os portos devem evoluir das funções tradicionais de facilitar as operações de carga e descarga, embora com maior eficiência, para se tornarem elos de uma cadeia logística maior, parte estratégica de um canal de distribuição global, e para serem bem-sucedidos, essas cadeias precisam alcançar um maior grau de integração (DE SOUZA et al., 2003), já que os portos exercem na cadeia logística serviços além do atendimento aos navios e às cargas (LUZ et al.,2018).

A integração dos portos no conceito de logística e da gestão da cadeia de suprimentos é bem argumentada por Bichou e Gray (2005), eles examinam a validade da terminologia convencional para classificar os portos, questionando a suposição de que os portos devem ser conceituados como mercados separados e empreendimentos operacionais e de negócios distintos. Bichou e Gray (2005) conceituaram o papel dos portos a partir de três perspectivas. Em primeiro lugar, do ponto de vista do canal de logística, o porto serve como um nó na interseção de transporte intermodal / multimodal e opera como um centro de logística para o fluxo de carga / passageiros. Em segundo lugar, do ponto de vista do canal de comércio, o porto é um local-chave em que o controle e a propriedade do canal podem ser identificados e / ou negociados. Em terceiro lugar, do ponto de vista do canal de abastecimento, o porto não apenas liga fluxos e processos externos, mas também cria padrões e processos próprios. Nesse contexto, os portos podem atuar como integrantes de uma cadeia logístico-portuária. 
De acordo com este contexto, formula-se a seguinte pergunta de pesquisa como proposta de trabalho:

Como é possível identificar o porto como integrante da cadeia logísticoportuária de produtos refrigerados e/ou congelados no Estado de Santa Catarina?

Para o atendimento desta pergunta de pesquisa, o objetivo geral deste trabalho é identificar o porto como um integrante de uma cadeia logístico-portuária de produtos refrigerados e/ou congelados em SC.

\section{REFERENCIAL TEÓRICO}

\subsection{Logística portuária}

Uma vez que os portos desempenham um papel funcional fundamental nas operações logísticas internacionais (ROBINSON, 2002), é nos portos onde muitas das oportunidades de negócios foram identificadas (PETTIT; BERESFORD, 2009). Tendo em visto essa importância, é fundamental o entendimento do conceito de logística portuária e qual é a fronteira de operação que ela engloba (ALMOTAIRI; LUMSDEN, 2009).

Os portos desempenham na cadeia de suprimentos global um papel importante e estratégico a partir do momento que grande parte do volume de exportação são remetidas por transporte marítimo internacional (KEEDI, 2011) e na Figura 1, elaborada por Pettit e Beresford (2009), pode-se compreender o papel dos portos na cadeia de suprimentos e a evolução nas últimas quatro décadas, com ênfase crescente nas atividades de valor agregado e integração gradual dos portos na cadeia de suprimentos.

Figura 1 - A integração de portos na cadeia global de suprimentos

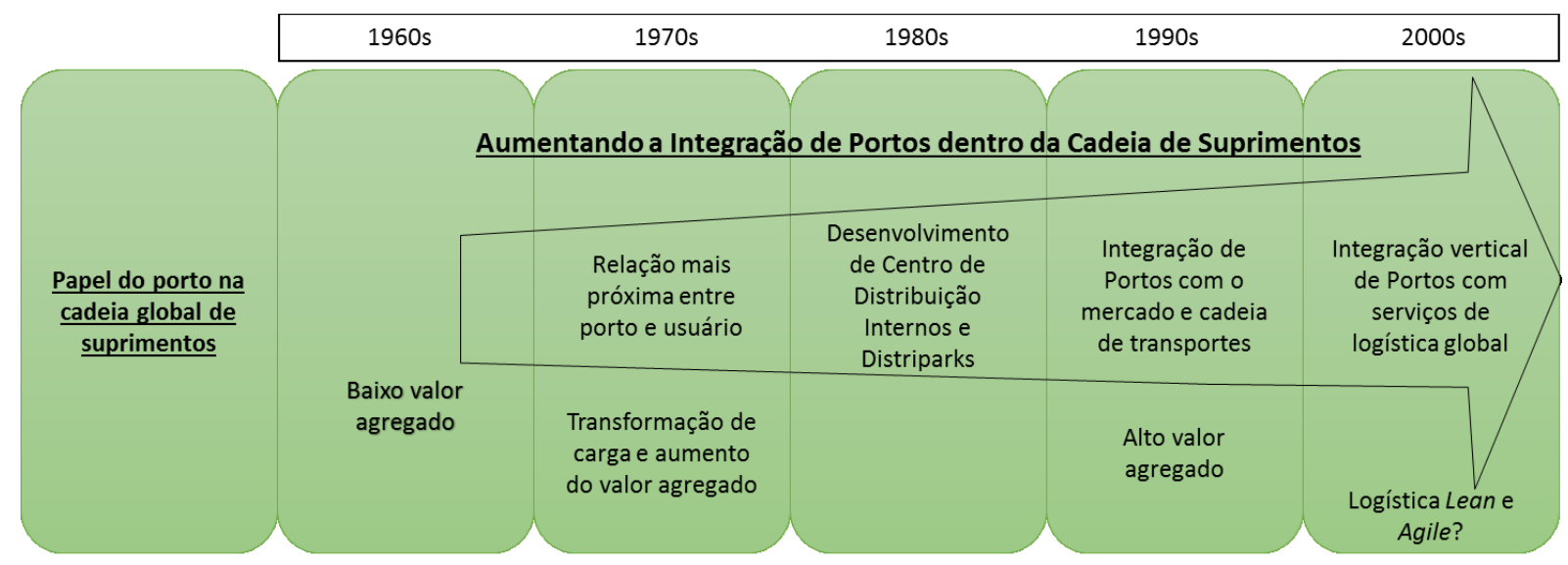

Fonte: Pettit e Beresford (2009)

Os portos desempenham um importante papel na gestão e coordenação do fluxo de bens e serviços, sendo o transporte parte integrante de toda a cadeia global de suprimentos. Dessa maneira, a competitividade de um porto não é determinada apenas na sua eficiência operacional, infraestrutura de área e equipamentos, e tecnologias, suas conexões caracterizadas por abrangência da hinterlândia, mas também é afetada pelas interfaces na cadeia de suprimentos (CARBONE; MARTINO, 2003). 
De acordo com Liu et al., (2008) o porto é o ponto principal na engenharia dos sistemas logísticos internacionais, adaptado a logística moderna, incorporando atividades como o transporte multimodal, comércio exterior, finanças, entre outras, e Bae (2012) afirma que a logística portuária se define como centros complexos relacionados aos produtos e serviços, e a rede de transporte interligada. Zouari e Khayech (2011), definem os portos como representando os fornecedores de serviços para os navios, para as mercadorias e os transportes do interior do país.

Fogliatti \& Fernandes (2010), delimitam o fluxo logístico de um terminal portuário que pode ser dividido em dois fluxos, o de importação e o de exportação. No primeiro, a carga é descarregada no terminal e, depois de verificada a documentação correspondente e as condições físicas da carga, é então enviada para uma área de armazenamento para ser retirada (se a carga veio em contêineres) ou para ser transportada como carga fracionada. No fluxo de exportação, a carga chega ao terminal ou em contêineres ou de forma fracionada. Se chegar em contêineres, estes são inspecionados depois de todos os documentos correspondentes serem processados. Se ambos os aspectos, os documentos e as condições físicas da carga, forem aprovados, a carga vai para uma área de armazenamento ou para a área de remessa.

\subsection{0 contêiner}

O contêiner exerce um papel importante na logística portuária, facilitando a movimentação dos mais diversos tipos de cargas no comércio internacional. Como uma embalagem que tradicionalmente é constituída em aço, alumínio ou fibra, é utilizada para o transporte unitizado de mercadorias, destinada para sistemas modernos de distribuição, e possuindo diversos tamanhos padronizados e normalizados para o transporte internacional (KEEDI; MENDONÇA, 2003; BALLOU, 2006).

Rojas (2014) descreve que operações de logística integrada, o principal equipamento é o contêiner, pois ele facilita vários tipos de combinações de transportes multimodais, pois a carga acondicionada em contêineres não exige manuseios custosos e possibilita o serviço porta a porta quando a combinação de modais utiliza transportes terrestres, Levinson (2008) reforça ao concluir que o contêiner trouxe um novo padrão de unitização de cargas para o comércio internacional.

Os tamanhos de contêineres mais comuns, medidos em pés, são os de 20 pés de comprimento (TEU) ou 40 pés de comprimento (FEU), podendo ser HC (High Cube) de alta cubagem, atendendo diversas finalidades de transportes de cargas, dentre elas as cargas perecíveis, como por exemplo carnes e miudezas refrigeradas e/ou congeladas, sendo armazenadas e transportadas em contêiner tipo Reefer, isolado termicamente, com motorização para resfriamento e/ou congelamento (LOPEZ; GAMA, 2011), esses contêineres necessitam de uma fonte geradora de energia elétrica externa para funcionar e devem permanecer conectados ao longo de sua viagem (DAVID; STEWART, 2010). Um exemplo de contêiner tipo Reefer está representado na figura 2 . 


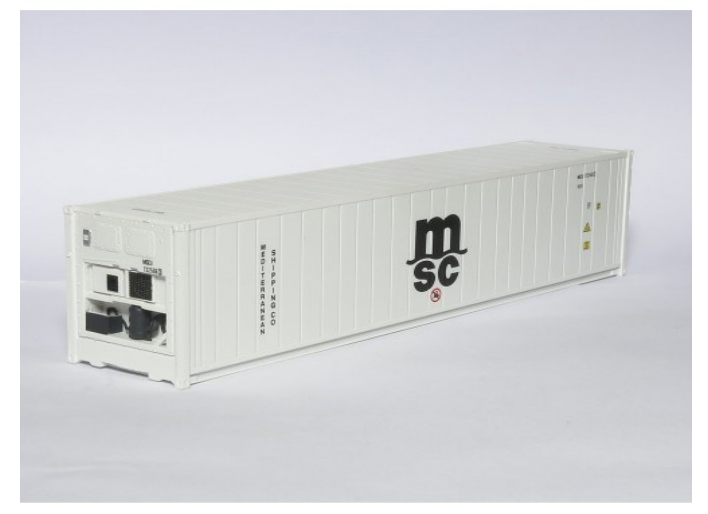

Fonte: MSC (2018).

O contêiner passa a ser uma referência internacional como embalagem e facilitador para o comércio internacional, nas operações de exportação e/ou importação.

\subsection{Exportação}

A gestão da cadeia de suprimentos global é essencialmente caracterizada por empresas exportadoras, destinando um percentual de sua produção para atender o mercado consumidor de outros países (DAVID; STEWART, 2010).

Lopez e Gama (2011), afirmam que a exportação sob o aspecto aduaneiro compreende quando ocorre a saída da mercadoria do território nacional, sendo a sua constatação a partir do momento de seu ingresso no veículo de transporte internacional, por exemplo de uma mercadoria conteineirizada, quando ingressa no navio cargueiro, Castro (2005) considera ainda que é uma atividade empresarial integrada com todos os agentes participantes do processo, como transportadores, operadores logísticos, aduana, órgãos fiscalizadores, terminal portuário, armador, entre outros, exigindo um intercâmbio de informações constantes.

$\mathrm{Na}$ figura 3 uma representação resumida de um canal de distribuição de exportação de uma carga qualquer, que a partir da empresa exportadora até o porto de origem do país da empresa, diversos agentes intermediários como transportadores, armazéns, operadores logísticos, aduana, e demais áreas que possibilitam a transferência da mercadoria até o embarque do transporte marítimo principal, com destino ao país importador. 
Figura 3 - Canal de distribuição de exportação de uma carga no país de origem

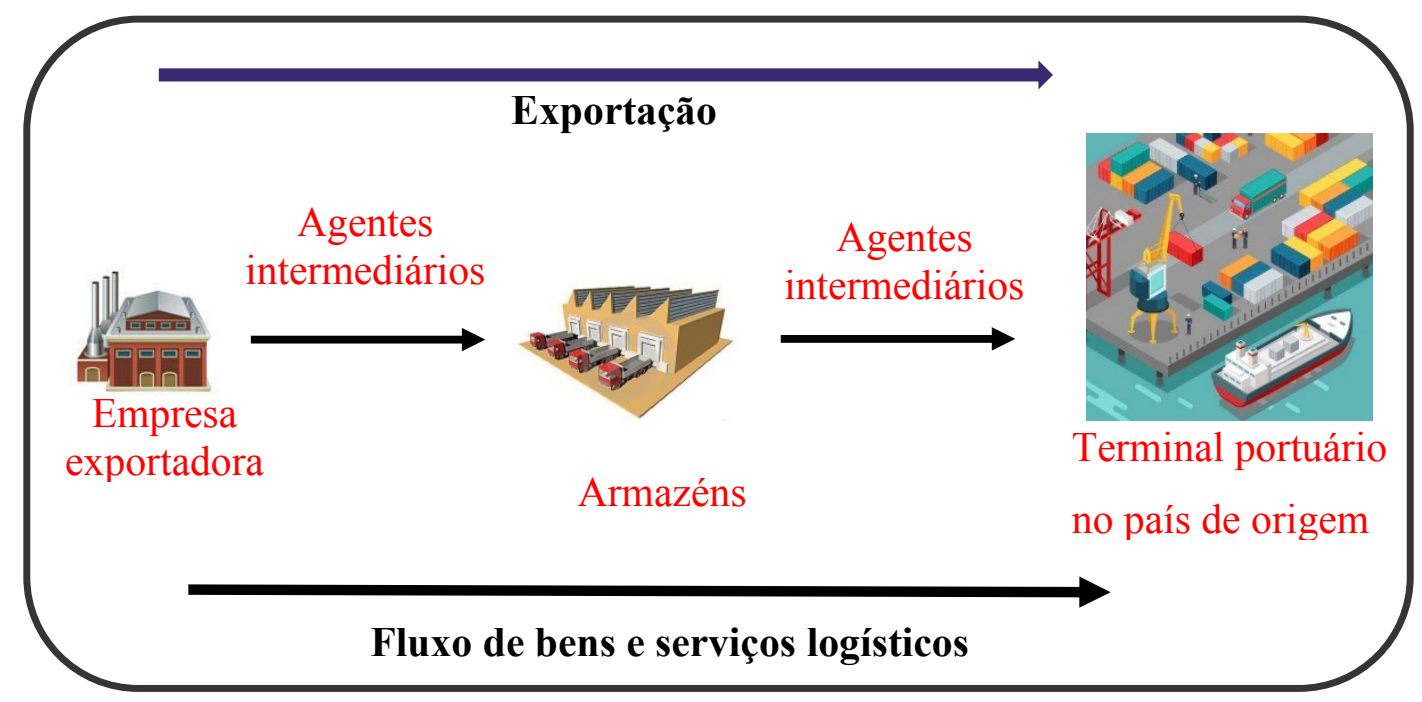

Fonte: Adaptado de Ballou (2012) e David e Stewart (2010).

Cada agente interveniente do canal desempenha um papel específico, mas dependente dos demais, desta forma, a eficiência da exportação depende do sucesso de seus membros atuando com sinergia na cooperação em suas atividades de forma a atingir o objetivo geral do canal, que é a chegada do produto ao mercado externo (LOPEZ; GAMA, 2011).

\subsection{Cadeia logístico-portuária}

Reconhecendo que os portos exercem um papel importante a desempenhar no contexto de integrar suas funções e operações às de suas cadeias de suprimentos, alguns autores evoluíram abordagens sobre o papel da logística e da cadeia de suprimentos dos portos (HARDING e JUHEL, 1997; MORASH e CLINTON, 1997; NOTTEBOOM e WINKELMANS, 2001; ROBINSON, 2002). Bichou e Gray (2004) observaram que a literatura associa dois conceitos à integração da cadeia de suprimento portuário, a saber, o intermodalismo e a integração organizacional. $O$ intermodalismo está relacionado a aspectos do gerenciamento de portos de contêineres (UNCTAD, 1995), ao desenvolver capacidades intermodais de sucesso, a presença de cooperação e eficiência organizacionais são parâmetros importantes (MORASH e CLINTON, 1997). No contexto da integração organizacional, o que parece ser o mais importante é o valor agregado que os portos podem oferecer (ROBINSON, 2002).

Carbone e De Martino (2003) descobriram que os parâmetros essenciais de integração dos portos em suas cadeias de suprimentos incluem tecnologias de informação e comunicação e aspectos relacionados ao valor agregado, incluindo relacionamento com o cliente e satisfação com relação aos serviços fornecidos.

Essa integração pode ser alcançada por meio da tecnologia da informação e da comunicação (compartilhamento de informações), bem como pela introdução de atividades e operações de valor agregado que reduziriam os custos. Um porto integrado na cadeia de suprimentos é caracterizado por uma comunicação constante, 
eliminação de desperdício e redução de custos nas operações, interconectividade e interoperabilidade da infraestrutura modal e operações e prestação de serviços de valor agregado, e satisfação do cliente (CARBONE e DE MARTINO, 2003).

Com base na premissa de que a medição da eficiência portuária se beneficiaria muito da inclusão dos princípios de logística e gerenciamento da cadeia de suprimentos, Bichou e Gray (2004) empreenderam uma investigação exploratória da medição do desempenho portuário com referência particular à logística, canal e a cadeia de suprimento.

Apesar da importância amplamente reconhecida de conceituar os portos como partes integrantes de uma estrutura logística e de gerenciamento da cadeia de suprimentos, o trabalho empírico sobre a integração de portos / terminais nas cadeias de suprimento tem sido limitado, compreendendo somente o porto como um sistema de entrada e saída, isoladamente (WANKE, 2013; CARBONE e DE MARTINO, 2003). Desta forma, Fogliatti \& Fernandes (2010), especificam que o porto possui a sua cadeia logística, voltada a atender uma complexidade de serviços que são necessários para que os materiais sejam movimentados no embarque e/ou desembarque, configurando assim a cadeia logística-portuária. Na figura 4, a representação da cadeia logístico-portuária onde o porto é um sistema, envolvendo uma transformação de serviços voltados para o embarque e/ou desembarque, e essa cadeia seria o fluxo de materiais desde a entrada no porto ate a saída.

Figura 4 - Cadeia logístico-portuária

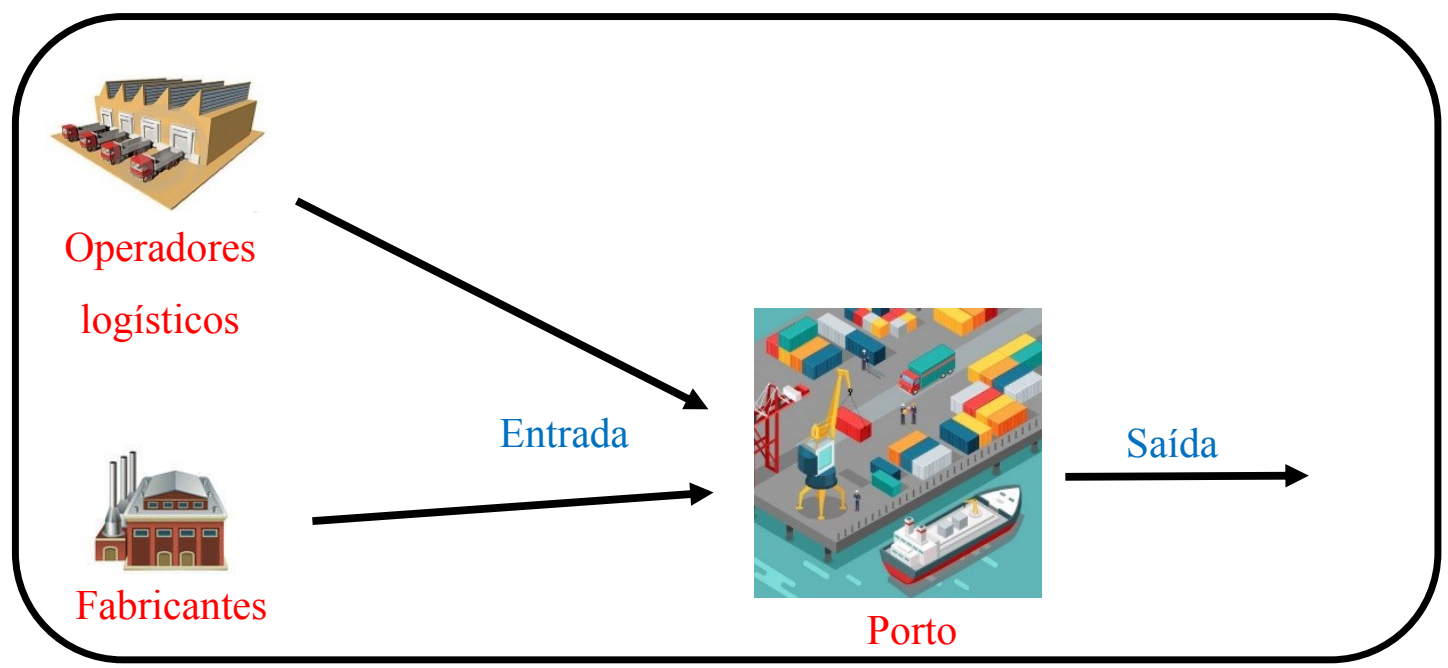

Fonte: Adaptado de Wanke, 2013; Carbone e De Martino, 2003.

Bichou e Gray (2004, p. 50) afirmaram que "muito da literatura defende o futuro dos portos como centros de cadeias logísticas". . . visualizam a integração logística das várias atividades realizadas.

Shao, Du e Lu (2016) afirmam que os portos são importantes elos da cadeia logística global, e que a cadeia logístico-portuária formada em torno do desenvolvimento de portos é a tendência geral de desenvolvimento do sistema portuário mundial, onde o porto é um elemento importante desta cadeia. A cadeia logístico-portuária é uma cadeia de fornecimento centralizada em empresas portuárias e sua eficiência operacional que influenciam o custo operacional e o nível de serviço dos sistemas logísticos envolvidos na cadeia, considerando a hinterlândia como a área influenciada pelo porto (SHAO;DU e LU, 2016). 
Lopez e Poole (1998), reforçam que os portos modernos são um complexo de empresas, uma "comunidade portuária", que oferecem uma gama de serviços de logística relacionados com ambos os produtos e os navios, formando uma cadeia de diversos outros agentes intermediários. A expressão "comunidade portuária" pode ser entendida por exemplo pela formação de todos os agentes intermediários a partir do momento que uma carga sai de uma empresa exportadora (considerando o conceito de hinterlândia real) por meio de serviços logísticos até a efetiva entrada no porto para o embarque ao navio.

A cadeia logístico-portuária ocupa uma posição central no sistema global de logística mundial não apenas porque o volume de carga que passa por vários portos é maior do que qualquer outro meio de transporte, mas também porque os portos conectam o transporte terrestre e hidroviário e fornecem um centro de informações sobre fontes de carga, tecnologias e serviços. O serviço de logística portuária envolve diversos atores - fornecedores de carga, clientes, operadores de terminais portuários, companhias de navegação e outras partes (TIAN et al., 2013).

Jie (2009) relata que a fim de competir nos mercados de hoje, os portos devem construir suas próprias cadeias de fornecimento, ou seja, as cadeias logísticoportuárias, define as cadeias de abastecimento dos portos como redes de prestadores de serviços de logística, incluindo as autoridades portuárias, aduanas, órgãos fiscalizadores, centros de armazenagens, companhias de navegação, operadores de terminais, empresas de estiva e operadores de transportes terrestres etc., que participam na prestação de serviços de logística integrada para os clientes.

No quadro 1, importantes características de duas cadeias, a de suprimentos e a dos portos, com as diferenças descritas é possível identificar uma importante visão sistêmica a partir do momento da definição da empresa focal das cadeias, enquanto uma cadeia de suprimentos tem fabricantes ou distribuidores a cadeia logísticoportuária tem os portos como empresa focal.

Quadro 1 - Diferenças entre cadeia de suprimentos e cadeia logístico-portuária

\begin{tabular}{|c|c|c|}
\hline Item & Cadeia de suprimentos & $\begin{array}{c}\text { Cadeias logístico- } \\
\text { portuárias }\end{array}$ \\
\hline Membros & $\begin{array}{c}\text { Fornecedores, Fabricantes, } \\
\text { Distribuidores, Varejistas e } \\
\text { Clientes. }\end{array}$ & $\begin{array}{l}\text { Portos, Transportadores, } \\
\text { Operadores Logísticos, } \\
\text { Proprietários de carga, } \\
\text { Agentes fiscalizadores. }\end{array}$ \\
\hline $\begin{array}{l}\text { Demanda de } \\
\text { recursos }\end{array}$ & $\begin{array}{c}\text { Material com poucas } \\
\text { categorias. }\end{array}$ & $\begin{array}{c}\text { Imaterial, transitório, } \\
\text { laborioso, com muitas } \\
\text { categorias. }\end{array}$ \\
\hline Criação de valor & Produção e montagem. & $\begin{array}{c}\text { Prestação de serviços } \\
\text { logísticos. }\end{array}$ \\
\hline Modo de operação & $\begin{array}{l}\text { Empurrado ou puxado. } \\
\text { Eficiente ou responsivo. }\end{array}$ & Puxado e responsivo. \\
\hline
\end{tabular}




\begin{tabular}{|c|c|c|}
\hline Empresa focal & Fabricantes ou distribuidores. & Portos \\
\hline $\begin{array}{c}\text { Avaliação de } \\
\text { desempenho }\end{array}$ & Baseado em produtos, & Baseada em serviços, \\
\hline Estabilidade & objetiva. & subjetiva. \\
\hline
\end{tabular}

Fonte: Adaptado de Jie (2009).

A cadeia logístico-portuária não fornece materiais e sim o fornecimento de serviços de logística como movimentação de cargas, manuseio e armazenamento, informação, rastreamento entre outros, Winter e Kellogg (1999) resumiram seis características dos produtos de serviços de uma cadeia, que são: Influência do cliente, intangibilidade, inseparabilidade da produção e consumo, heterogeneidade, perecibilidade e intensidade de trabalho, os serviços são imateriais, não permitindo a armazenagem, são consumidos no momento da produção.

O ponto de partida para o desenvolvimento do modelo proposto em atendimento aos objetivos deste trabalho, inicia-se com o mapeamento da cadeia de suprimentos de produtos refrigerados e/ou congelados em Santa Catarina.

\section{PROCEDIMENTOS METODOLÓGICOS}

O caminho a ser percorrido desta pesquisa pelo autor auxilia no entendimento dos procedimentos metodológicos, e das principais etapas de construção deste trabalho. O quadro 2 detalha a trajetória que foi percorrida e o procedimento metodológico.

As ações da trajetória deste trabalho estão destacadas no quadro 2, na coluna A os principais tópicos do referencial teórico que servirão de sustentação para formulação de conceitos, e propostas da cadeia logístico-portuária, na coluna $B$, a compilação e mapeamento das principais etapas da referida cadeia, na coluna $\mathrm{C}$, a aplicação dos questionários modelos 1 e 2, conforme os apêndices $A$ e $B$ de consulta aos experts profissionais para legitimar e por intermédio das compilações e ajustes, reconhecer o porto como integrante de uma cadeia logístico-portuária.

Quadro 1 - Trajetória da pesquisa

\begin{tabular}{|c|c|c|}
\hline A.Teoria/Bibliometria & B.Desenvolvimento/Empírico & C.Prática \\
\hline $\begin{array}{c}\text { Conceito } \\
\text { Logística portuária } \\
\begin{array}{c}\text { Cadeia logístico- } \\
\text { portuária }\end{array}\end{array}$ & $\begin{array}{c}\text { Mapeamento da cadeia } \\
\text { logístico-portuária em SC. }\end{array}$ & \multicolumn{2}{|c|}{ Questionários 1 e 2} \\
\hline & Compilação + ajustes & $\begin{array}{c}\text { Consulta aos experts } \\
\text { para legitimação }\end{array}$ \\
\hline
\end{tabular}

Fonte: Adaptado LDL - Laboratório de Desempenho Logístico - UFSC (2018). 
Para o atendimento da pesquisa teórica e a bibliometria é necessário desenvolver a pesquisa bibliográfica.

A pesquisa bibliográfica busca embasar e fortalecer sobre um determinado tema (CERVO et al., 2014), que neste trabalho se refere a avaliação de desempenho de uma cadeia logístico-portuária, optou-se por realizar uma pesquisa bibliométrica, de caráter qualitativo e científica seguindo os passos da coluna $A$, do quadro 2 . A pesquisa bibliométrica foi realizada com base nas orientações de Okubo (1997), que explica que a bibliometria tem por objetivo medir o resultado da investigação científica e tecnológica por meio de dados derivados.

No que se refere à operacionalização da pesquisa e seleção do portifólio bibliográfico foram utilizadas cinco bases de dados sobre o tema, segundo a base de consultas da CAPES (consultado em 06 de agosto de 2018 em http://www.periodicos.capes.gov.br/).

Bases de dados consultadas: Scopus, Emerald, Ebsco, Science Direct e Scielo.

Foram selecionadas palavras chaves alinhadas com o quadro 2 da seguinte forma:

a) Em língua inglesa

- port logistics concept

- port logistics chain

- port logistics

b) Em lingua portuguesa

- Conceito logístico-portuário

- Conceito de hinterlândia

- Cadeia logístico-portuária

Nas tabelas 1 e 2, a divisão por palavras chaves da quantidade de artigos coletados, em português e em inglês.

Tabela 1 - Quantidade de artigos por palavras chaves - Em português

\begin{tabular}{|l|c|}
\hline \multicolumn{1}{|c|}{ Palavras chaves } & Quantidade de artigos \\
\hline Conceito logístico-portuário & 0 \\
\hline Cadeia logístico-portuária & 0 \\
\hline Logística portuária & 01 \\
\hline Total & $\mathbf{0 1}$ \\
\hline
\end{tabular}

Fonte: elaborado pelo autor (2018).

Tabela 2 - Quantidade de artigos por palavras chaves - Em inglês

\begin{tabular}{|l|c|}
\hline \multicolumn{1}{|c|}{ Palavras chaves } & Quantidade de artigos \\
\hline Port logistics concept & 03 \\
\hline Port logistics chain & 23 \\
\hline Port logistics & 431 \\
\hline Total & $\mathbf{4 5 7}$ \\
\hline
\end{tabular}

Fonte: elaborado pelos autores (2018). 
Foi utilizado o gerenciador EndNote para agrupar, selecionar as duplicidades e melhor separar para a leitura dos títulos e resumos.

Após descartadas as duplicações e analisados os títulos e resumos de cada artigo alinhados a temática deste trabalho, chegou-se a um resultado de $\mathbf{3 8}$ artigos selecionados.

Selecionados os artigos, os mesmos foram analisados com o intuito de classificar as pesquisas já feitas na área, bem como identificar os conceitos importantes a serem discutidos neste trabalho. Além dos artigos selecionados, foram utilizadas fontes teóricas em livros com autores renomados no contexto do tema deste trabalho.

Como base de conhecimento empírico, a consulta com especialistas profissionais no tema deste trabalho se faz relevante para legitimar a teoria com a prática. Importante é definir o uso da expressão "expert", que segundo o Dicio (2018) trata-se de um especialista, pessoa cujo conhecimento excessivo a faz entender ou dominar certa área prática e/ou teórica, para Significados (2018) expert é uma pessoa com um conjunto de habilidades e conhecimentos em um sistema, que domina conteúdos e com muita experiência.

Foram definidos e consultados dentro da delimitação do tema deste trabalho os experts nas áreas específicas de atuação conforme o quadro 3 que segue:

Quadro 3 - Experts da cadeia logístico-portuária

\begin{tabular}{|l|l|}
\hline $\begin{array}{l}\text { Expert - Nome completo não } \\
\text { revelado }\end{array}$ & $\begin{array}{l}\text { Experiências/Empresa (não revelada) /Área } \\
\text { de atuação }\end{array}$ \\
\hline Héder & $\begin{array}{l}\text { Desenvolve atividade em um Porto do } \\
\text { complexo portuário de Itajaí há mais de 38 } \\
\text { anos, já ocupou a função de Diretor } \\
\text { Operacional por diversos anos, atualmente, } \\
\text { desenvolve a função de Assessor da } \\
\text { Superintendência do Porto de Itajaí. }\end{array}$ \\
\hline Jorge & $\begin{array}{l}\text { Gestor operacional em um Porto do complexo } \\
\text { portuário de Itajaí. Profissional com } \\
\text { experiência em mais de 12 anos em } \\
\text { planejamento, coordenação e execução de } \\
\text { operações portuárias. }\end{array}$ \\
\hline Couto & $\begin{array}{l}\text { Gestor de processos de armazenagem, } \\
\text { movimentação de cargas e embarques no } \\
\text { berço atracadouro, em uma empresa } \\
\text { operadora logística do complexo portuário de } \\
\text { Itajaí. }\end{array}$ \\
\hline Fogaça & $\begin{array}{l}\text { Consultor. Experiência profissional de mais de } \\
\text { 25anos na área industrial, educacional e de } \\
\text { prestação de serviços de consultoria em } \\
\text { terminais portuários. Docente em cursos de } \\
\text { Graduação. }\end{array}$ \\
\hline Giovani & $\begin{array}{l}\text { Profissional com mais de 20 anos de } \\
\text { experiência logística em empresas de } \\
\text { produção animal. Experiência em gestão de } \\
\text { operações logísticas, cadeia de } \\
\text { armazenagem, expedição e transportes. }\end{array}$ \\
\hline
\end{tabular}




\begin{tabular}{|l|l|}
\hline & $\begin{array}{l}\text { Atualmente é Gerente de operações logísticas } \\
\text { em uma empresa genuinamente catarinense } \\
\text { que está há } 70 \text { anos no mercado de produção } \\
\text { animal de bovinos e suínos, exportadora } \\
\text { para diversos países. }\end{array}$ \\
\hline Gabriela & $\begin{array}{l}\text { Profissional com mais de } 14 \text { anos de } \\
\text { experiência em planejamento e controle } \\
\text { logístico de transportes internacionais, } \\
\text { documentação de exportação, e controle dos } \\
\text { custos logísticos na cadeia produtiva. } \\
\text { Atualmente é coordenadora de controle } \\
\text { logísticos em uma empresa em Santa } \\
\text { Catarina com mais de } 60 \text { anos no mercado de } \\
\text { produção animal, controlada por um } \\
\text { importante grupo internacional, líder mundial } \\
\text { em processamento de carne bovina, ovina e } \\
\text { de aves. }\end{array}$ \\
\hline
\end{tabular}

Fonte: Elaborado pelos autores (2018).

O método de pesquisa especificado é um estudo de caso que segundo Severino (2016) é considerado representativo e significativo, apto a ser fundamentado com uma generalização, sendo os dados coletados e registrados com o necessário rigor e seguindo todos os procedimentos da pesquisa de campo;

A coleta de dados é uma tarefa importante na pesquisa, sendo necessário definir o instrumento que realizará a coleta diante de uma população definida sob critérios específicos (CERVO et al., 2014; MARCONI; LAKATOS, 2017). Um dos instrumentos mais utilizados e de maior exatidão é o questionário, composto por indagações de sequência lógica e relevantes na obtenção de dados ao tema proposto pelo trabalho (SEVERINO, 2016), sendo que as perguntas devem conduzir de forma facilitada as respostas, porém sem induzir e/ou conduzir obrigatoriamente no desejo do investigador que a aplica (CERVO et al., 2014; MARCONI; LAKATOS, 2017).

As perguntas abertas proporcionam respostas de maior profundidade, ou seja, dá ao sujeito uma maior liberdade de resposta, podendo esta ser redigida pelo próprio, oferecendo uma maior liberdade ao respondente (MARCONI; LAKATOS, 2017).

A principal técnica de pesquisa para a coleta de dados neste trabalho é a aplicação de questionários com questões abertas para a maior coleta de informações acerca da temática do objetivo geral.

\section{MAPEAMENTO DA CADEIA DE SUPRIMENTOS DE PRODUTOS REFRIGERADOS E/OU CONGELADOS EM SC}

A vocação do Estado de Santa Catarina para o desenvolvimento industrial vem se consolidando com a formação de polos líderes em setores como alimentos e bens de capital, conectados ao mercado mundial (INVESTESC, 2018), na produção agrícola, animal e do agronegócio os números são reveladores de um Estado produtor e de liderança em alguns setores em relação a produção nacional, como é o caso da produção animal, sendo o maior produtor nacional de carne suína e de pescados e o segundo em abate de frangos do país em 2017 (INVESTESC, 2018). 
Na figura 5, as principais exportações do estado de Santa Catarina por grupos de produtos realizadas no ano de 2017, que perfazem um total de US\$ 8,51 bilhões de dólares americanos, não incluindo os valores com fretes internacionais, somente o valor do frete até o porto de origem na saída do país, ou seja, o valor FOB.

Do total das exportações realizadas ainda de acordo com a figura 5, o grupo de carne de frango congelada, fresca ou refrigerada incluindo as miudezas, foram de $17 \%$, de maior destaque em relação aos demais grupos de produtos, e se incluir também o grupo de carne de suíno congelada, fresca ou refrigerada com $7 \%$, totalizam juntos $24 \%$, com um valor aproximadamente de US\$2 bilhões de dólares americanos, um percentual representativo do negócio de produção animal para o estado de Santa Catarina.

Figura 5 - Exportações em SC por grupo de produtos em 2017

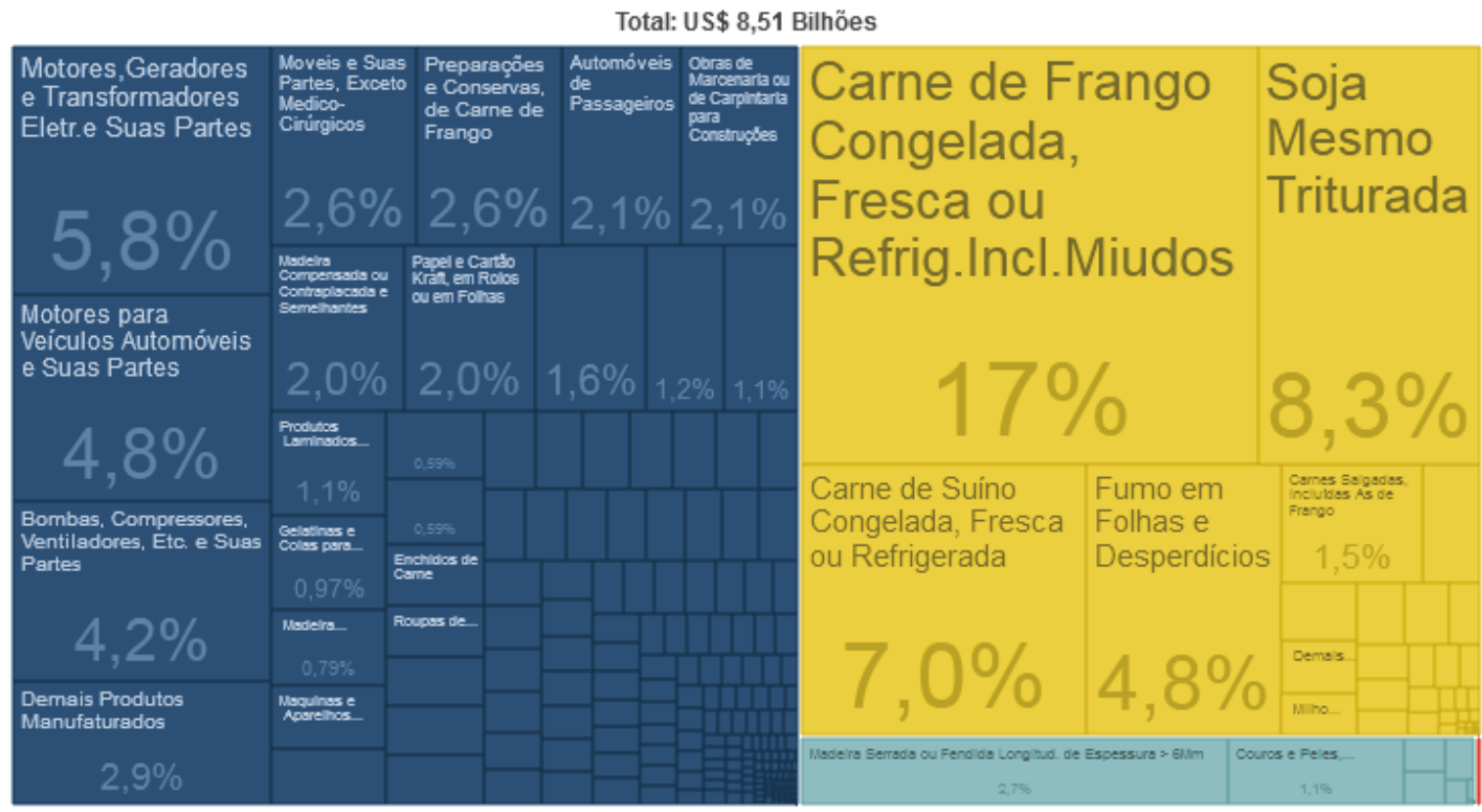

:

*Variações em relação ao ano anterior. 0 tamanho dos retângulos é proporcional à participação em relação ao Valor FOB total.

Fonte: MDIC - Ministério do Desenvolvimento, Indústria e Comércio (2018).

A quantidade exportada vem crescendo ano a ano, no primeiro trimestre de 2018, já foram embarcadas 1,2 mil toneladas de carne bovina, o que representa quatro vezes mais do que no mesmo período de 2017. Nos primeiros três meses de 2018, o faturamento com as exportações do produto passou de US\$4,1 milhões de dólares americanos, ou seja, $277,2 \%$ a mais do que no primeiro trimestre do último ano. $O$ principal destino para a carne bovina catarinense é Hong Kong, que compra $77 \%$ do total exportado pelo Estado (GOVERNO DE SANTA CATARINA, 2018).

Para escoar a produção animal exportada catarinense, o papel dos portos catarinenses são estratégicos, e dentre as principais mercadorias movimentadas pelo Complexo portuário de Itajaí estão: frangos congelados e suas miudezas (maior porto 
exportador do Brasil); e carne congelada e suas miudezas em geral. Merece destaque a movimentação de contêineres, que coloca o Complexo Portuário de Itajaí na segunda posição do ranking nacional, atrás apenas do Porto de Santos (EMBRAPA, 2018).

Localizado no estado de Santa Catarina, nos municípios de Itajaí e Navegantes, no litoral centro-norte do estado, o complexo portuário de Itajaí é composto pelo Porto público de Itajaí e por seis TUPs, Teporti Terminal Portuário de Itajaí S.A. (TUP Teporti); Poly Terminais S.A. (TUP Poly Terminais); Trocadeiro Portos e Logística Ltda. (TUP Trocadeiro); Barra do Rio Terminal Portuário S.A. (Terminal Barra do Rio); Terminal Portuário Braskarne (TUP Braskarne); e Portonave S.A. Terminais Portuários de Navegantes (TUP Portonave), que ficam às margens do Rio Itajaí-Açu que, para fins de padronização, adotou-se como margem direita aquela que abriga o Porto Público de Itajaí e demais TUPs localizados em Itajaí, enquanto que o TUP Portonave, situado em Navegantes, encontra-se na margem esquerda do Rio. A Figura 6 ilustra as posições de tais instalações (SNP, 2018).

Figura 6 - Complexo portuário de Itajaí - SC

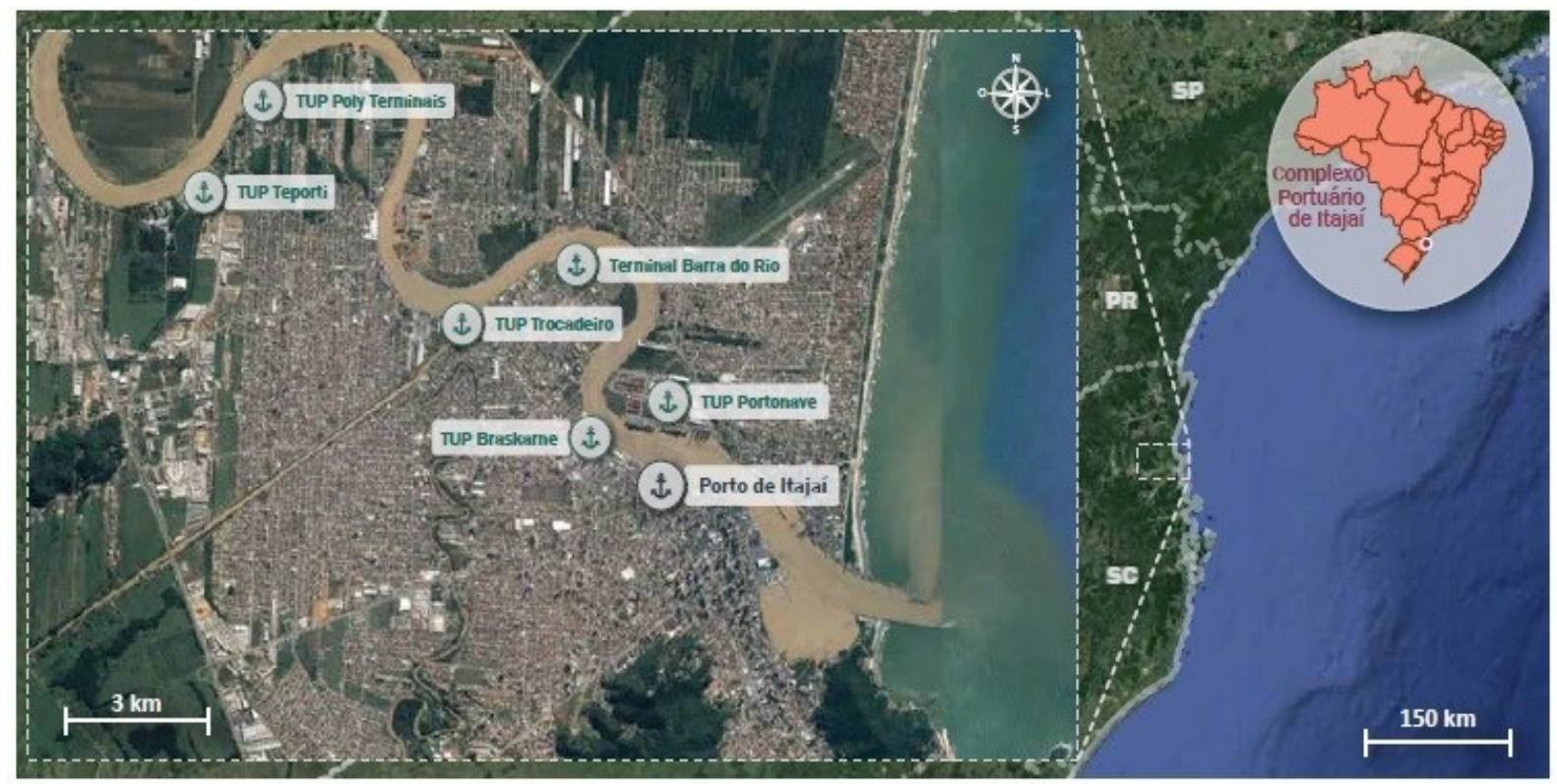

Fonte: SNP - Secretaria Nacional dos Portos (2018).

As principais etapas do mapeamento da cadeia de suprimentos de produtos refrigerados e/ou congelados em Santa Catarina correspondem aos estudos elaborados por diversos autores (HARDING e JUHEL, 1997; MORASH e CLINTON, 1997; NOTTEBOOM e WINKELMANS, 2001; ROBINSON, 2002), que reconhecem que os portos exercem importante papel de suas funções e das suas operações nas suas próprias cadeias logístico-portuárias, bem como dentro especificamente da area física de um porto nas suas principais macros etapas de atividades operacionais a partir do momento que uma carga adentra a região portuária, assim divididas em: Recebimento do produto, armazenagem, pátio de operação e o carregamento (HEAVER, 2002; ROBINSON, 2002; CARBONE; DE MARTINO, 2003; MARLOW; PAIXÃO, 2003; PAIXÃO; MARLOW, 2003; BICHOU; GRAY, 2005; TONGZON; HENG, 2005; PANAYIDES, 2006; ROBINSON, 2006; WANG; CULLINANE, 2006), também considerando cargas advindas do interior sob o conceito de hinterlândia real 
defendida por (FERRARI et al.,2010), assim como Pizzolato et al. (2010), que considera a hinterlândia real como a região que recebe e envia mercadorias para um único porto, ou seja, da origem da carga até o porto, independente da distância física, desta forma foi elaborada a cadeia logístico-portuária de produtos refrigerados e/ou congelados em SC, representada na figura 7, na qual a carga parte da Indústria do produto analisado, que ora é representado por produtos refrigerados e/ou congelados, do interior do estado de SC, segue por caminhão transportando o conteiner reefer até um operador logístico, depois de armazenar e efetuar o serviço de inspeção na carga, segue por caminhão até as dependências do porto, após adentrar no porto, a carga segue nas macros etapas definidas, sendo o recebimento (inspeção visual e documental), armazém e movimentação interna no porto, pátio de ordenação de cargas para embarque e a operação de carregamento no navio programado, e na sequência no processo denominado expedição, que ocorre o transporte marítimo internacional.

Figura 7 - Cadeia logístico-portuária de Produtos refrigerados e/ou congelados em SC

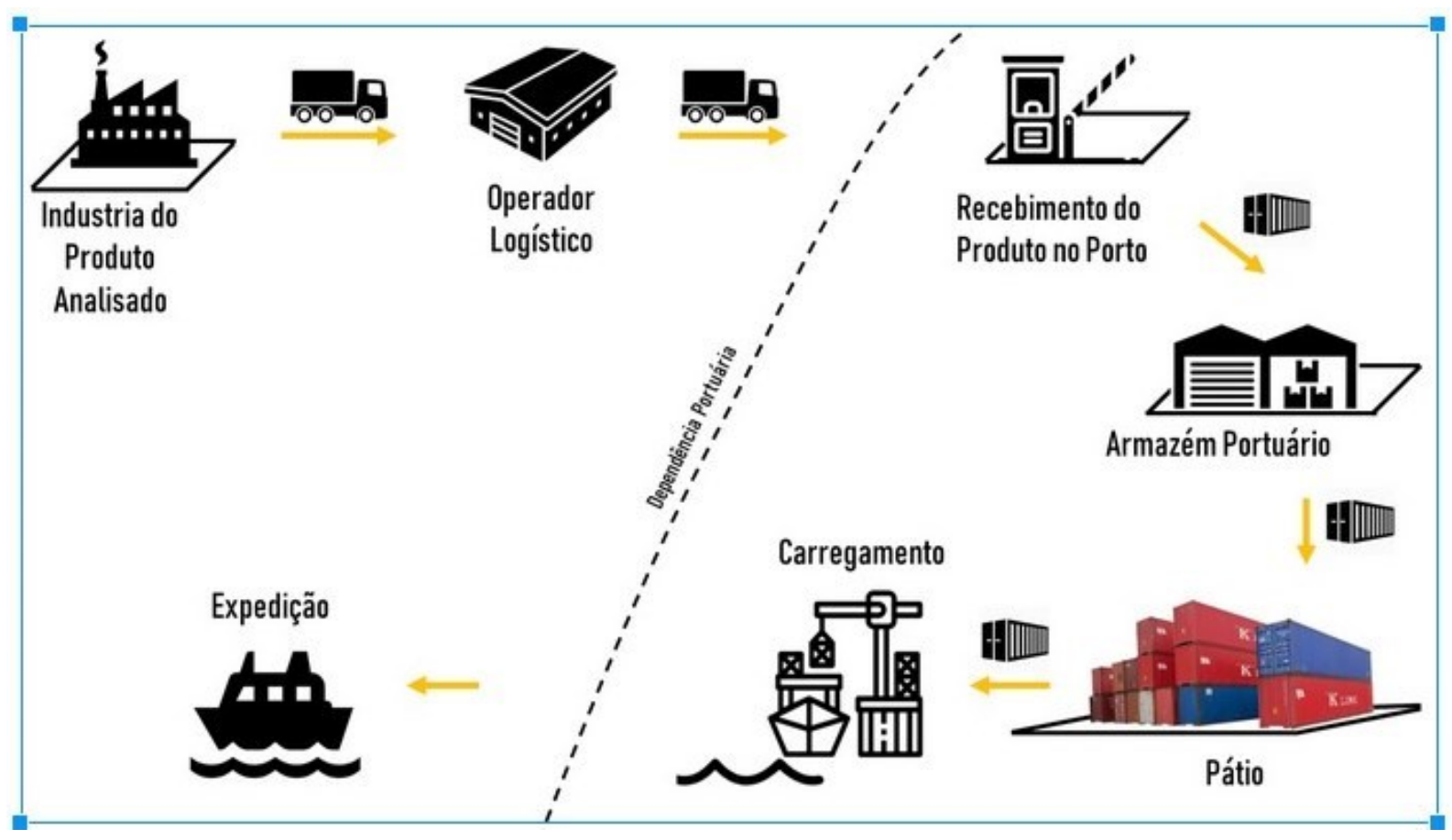

Fonte: GELOG (2018).

Os conhecimentos acerca das atividades desta cadeia logístico-portuária estão indagados nos questionários modelo 1 e 2, aplicados aos experts específicos, e com base nas respostas, a legitimação das contribuições teóricas com a prática do mercado dos experts.

\subsection{Aplicação dos questionários 1 e 2}

Os questionários modelo 1 e 2 aplicados aos experts estão posicionados conforme a figura 8 , na dependência portuária foi utilizado o questionário modelo 1 aos experts com conhecimento em gestão e operação portuária a fim de buscar mais conhecimentos e legitimação da proposta de sub divisão das macros etapas de processos de um porto, para as empresas exportadoras de produção animal foi utilizado o questionário modelo 2 aos experts com conhecimento em gestão e 
operação da logística de seus produtos, utilizando os portos como o meio principal para a exportação. As questões abertas permitiram que os respondentes usassem suas próprias palavras nas respostas, sendo reveladoras para o acréscimo de conhecimento e facilitadoras para legitimar a proposta deste trabalho, oferecendo aos respondentes a oportunidade de se expressarem para reclamarem sobre uma experiência ruim ou elogiarem uma experiência boa.

Figura 8 - Posicionamento na cadeia dos questionários 1 e 2 aplicados

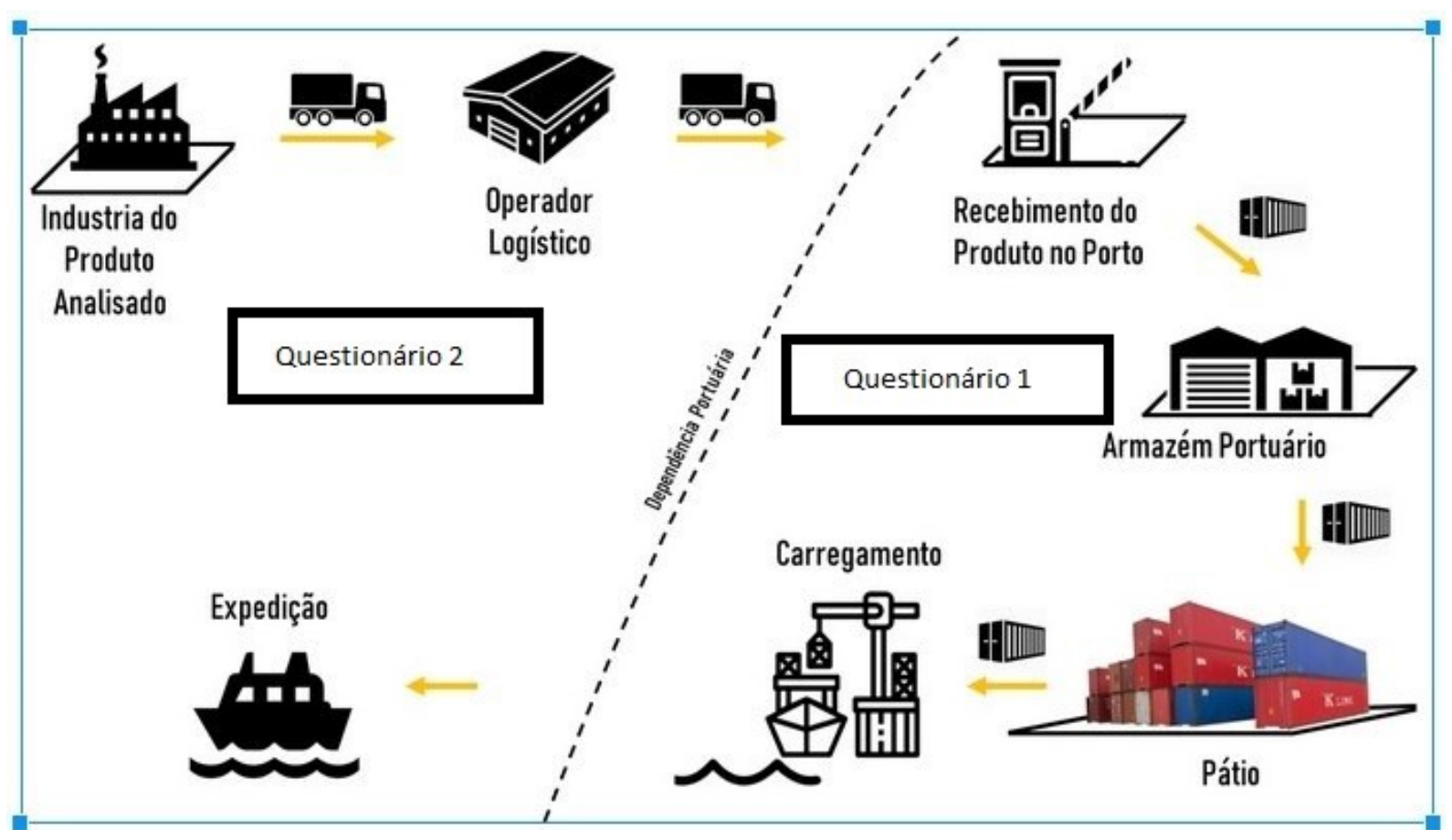

Fonte: GELOG (2018).

A seguir os resultados da aplicação dos questionários 1 e 2 e os seus respectivos resultados.

\subsection{Resultados da aplicação dos questionários 1 e 2}

Com base nas respostas deste questionário, e considerando a revisão nas macros etapas pelos experts, segue a legitimação com a participação do mercado profissional (experts), incluindo/alterando partes importantes da área delimitada do porto, incluindo a retroarea, a área de segurança no entorno portuário, e a delimitação da dependência portuária, na qual os experts também contribuíram com conhecimentos acerca do funcionamento das macros etapas do Porto, definidas em Recebimento, Armazenagem e Movimentação, e Carregamento e Embarque.

A Segurança envolve uma grande área, da dependência portuária, que se relaciona com a carga e o patrimônio do Porto. Também faz parte a retroárea, uma área adjacente à dependência portuária que possui os serviços de apoio a movimentação e/ou armazenagem de cargas do terminal portuário, podendo executar serviços de operação, com carga de exportação, embarcados em contêiner (DAVID; STEWART, 2010). 
O pátio representado na cadeia logístico-portuária, é a área total dentro da delimitação portuária, onde consta a Armazenagem (em local fechado e/ou aberto) e a Movimentação dos equipamentos, veículos e das cargas (WANKE, 2013).

As principais atividades logísticas da indústria até a dependência portuária legitimadas pelos experts no questionário 2, que fazem parte da cadeia logísticoportuária de produtos refrigerados e/ou congelados em SC, a partir da indústria exportadora de produção animal que ocorre em duas configurações de percurso/atividades, assim especificadas:

a) A carga exportada sai da indústria via modal rodoviário e vai até um operador logísticos, que realiza serviços de crossdocking, armazenagem e transporte, após as atividades do operador logístico, segue via modal rodoviário até a dependência portuária onde ocorrerá as macros etapas já definidas e legitimadas pelos experts; e

b) A carga exportada sai da indústria via modal rodoviário e vai direto até a dependência portuária onde ocorrerá as macros etapas já definidas e legitimadas pelos experts, ou caso necessite para aguardar liberação/inspeção, utiliza-se na retroárea um serviço de armazenagem próprio ou de terceiros, antes de adentrar na dependência portuária.

As duas configurações atendem as indústrias exportadoras de produtos refrigerados e/ou congelados consultadas pelos seus experts, considerando que nestes caminhos as cargas se originam de plantas industriais diferentes em relação à distância, que compreendem num raio de até 600 quilômetros, até a dependência portuária que ora está delimitada no complexo portuário de Itajaí no estado de Santa Catarina.

\subsection{A cadeia logístico-portuária legitimada}

Concluída a legitimação das principais atividades logísticas da indústria exportadora de produção animal por meio do questionário 2 , a figura 9 representa a cadeia logístico-portuária desenvolvida nesta etapa do trabalho, com carga originada da indústria exportadora de produção animal em Santa Catarina, que se utiliza de pelo menos dois caminhos logísticos ora representados via operador logístico ou diretamente à dependência portuária com opção de serviço de armazenagem na retroárea, sendo que após a carga a ser exportada adentrar na dependência portuária, quatro macro etapas foram definidas como recebimento, armazenagem e movimentação, e carregamento e embarque, seguindo a expedição para o porto de destino em outro país. Cabe ressaltar o acréscimo de duas áreas legitimadas pelos experts consultados, a retrorárea, local este próximo a dependência portuária na qual são ofertados serviços logísticos de armazenagem, operações de transbordos de cargas, despachos aduaneiros, dentre outros, como opção para embarcadores que necessitam da realização destes serviços ao adentrarem ou saírem da dependência portuária, e a área de segurança, envolvendo os seguros de patrimônio e de cargas, bem como a gestão de riscos com a aplicação de normas para a prevenção e/ou atuação em casos de sinistros, dentro da dependência portuária e também dos serviços que são realizados na retroarea. 
Figura 9 - Cadeia logístico-portuária de produtos refrigerados e/ou congelados em SC

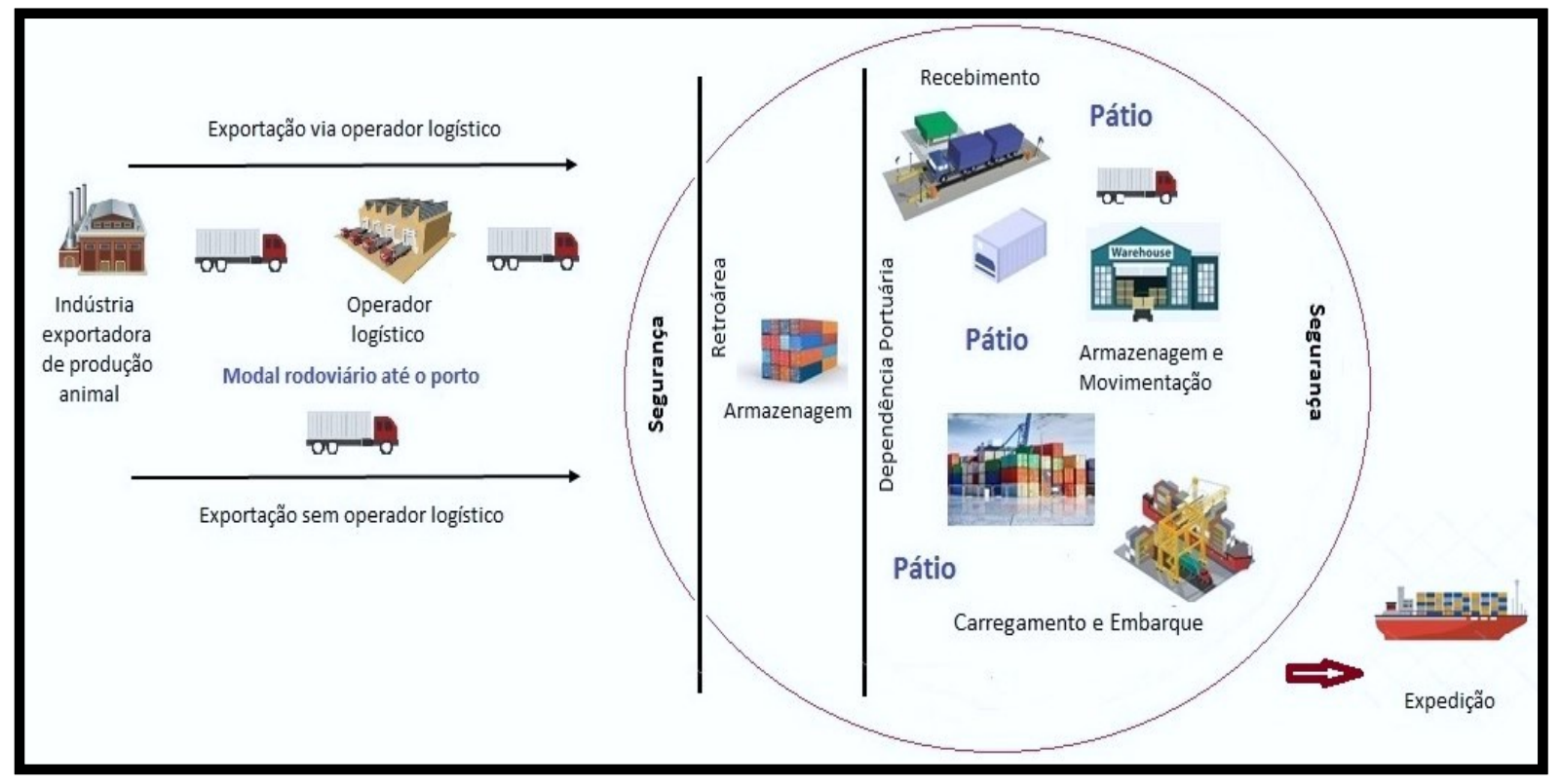

Fonte: Elaborado pelos autores (2018).

Jie (2009) reforça a cadeia logístico-portuária sendo o porto (dependência portuária) a empresa focal, um concentrador de serviços e um nó complexo em atividades, onde os demais membros participantes envolvendo os proprietários de cargas, aqui representados pelas indústrias exportadoras de produção animal, os transportadores, operadores logísticos e os agentes fiscalizadores, se voltam a produzir serviços para atender as necessidades de um embarque em um porto, e a criação de valor desta cadeia é na prestação de serviços logísticos, sendo que a sua avaliação de desempenho está baseada em serviços com características subjetivas para medir o seu desempenho, assim como Winter e Kellogg (1999) que descrevem os serviços logísticos como imateriais, não permitindo a armazenagem e são consumidos no momento da produção de todas as atividades da cadeia logísticoportuária.

\section{CONSIDERAÇÕES FINAIS}

O objetivo geral de identificar o porto como um integrante de uma cadeia logístico-portuária de produtos refrigerados e/ou congelados em SC foi cumprido, ao se estabelecer a construção por intermédio de uma sustentação teórica e legitimada com experts do mercado profissional.

O mapeamento da cadeia de suprimentos de produtos refrigerados e/ou congelados em SC foi identificado a partir do embarque da empresa produtora e exportadora até o momento do embarque, que neste estudo foi delimitado no complexo portuário de Itajaí em SC. No campo científico observou-se uma contribuição conceitual de uma cadeia onde a empresa focal é o porto e os demais agentes participantes estão conectados em função da complexidade de atividades logísticas envolvidas no processo de exportação. No campo prático, os experts consultados compreenderam que esta cadeia é existente e legitimaram a proposta conceitual de uma cadeia logístico-portuária por intermédio dos questionários modelo 1 e 2 aplicados, conforme os apêndices A e B. 
O reconhecemento do porto como parte integrante da cadeia logístico-portuária foi cumprido, a partir de uma construção teórica das principais etapas desta cadeia e por intermédio de uma representação em formato de figura, que foi legitimada e ajustada conforme as respostas dos experts por intermédio dos questionários modelo 1 e 2 aplicados, onde se definiu e identificou-se as principais etapas a partir do embarque de uma carga na empresa produtora e exportadora em SC e adentrando ao recinto portuário em quatro macros etapas, bem como com o acréscimo de uma retroárea que fica próxima ao entorno portuário.

Este trabalho contribuiu também para a ampliação do conhecimento da área de logística portuária, na medida em que lacunas do conhecimento científico foram identificadas e preenchidas. Uma destas contribuições foi a definição da cadeia logístico-portuária de produtos refrigerados e/ou congelados em SC, estabelecendo características específicas e relevantes da logística e do funcionamento de portos nesta cadeia. Outra contribuição foi a identificação de macros etapas dos processos da cadeia logístico-portuária, que orientam e servem de base para medidas avaliativas do seu desempenho.

Como sugestão de extensão deste trabalho, surgem algumas alternativas. A primeira delas está relacionada com o sequenciamento deste trabalho para que sejam possíveis ações práticas com o objetivos de avaliar o desempenho da cadeia logísticoportuária em uma série histórica em SC, para obtenção de uma média avaliativa mais assertiva quanto ao desempenho de toda a cadeia.

\section{REFERÊNCIAS}

$B A E, H . S$. The influencing factors of logistics integration and customer service performance for value creation of port logistics firms. Asian Journal of Shipping and Logistics, v. 28, n. 3, p. 345-368, 2012.

BAGGHI, P., and H. VIRUM. 1998. "Logistical Alliances: Trends and Prospects in Integrated Europe.” Journal of Business Logistics 19 (1): 191-213.

BALLOU, Ronald H. Logística Empresarial. Transportes. Administração de Materiais. Distribuição Física. Atlas:São Paulo. 2012.

BICHOU, K. and GRAY, R.,2004. A logistics and supply chain management approach to port performance measurement. Maritime Policy \& Management, 31, 47-67.

BICHOU, K. and GRAY, R., 2005. A critical review of conventional terminology for classifying seaports. Transportation Research A, 39 (1), 75-92.

BOWERSOX, D. J.; CLOSS, D. J.Logística empresarial. O processo de integração da cadeia de suprimento. São Paulo: Atlas, 2001.

BUCKLEY, P., and P. GHAURI. 2004. "Globalization, Economic Geography and the Strategy of Multinational Enterprises." Journal of International Business Studies 35 (2): 81-98. 
CARBONE, V. and DE MARTINO, M., 2003. The changing role of ports in supplychain management: an empirical analysis. Maritime Policy and Management, 30 (4), 305-320.

CASTRO, J. Augusto de. Exportação. Aspectos práticos e operacionais. Aduaneiras: São Paulo. 6ª ed., 2005.

CERVO, Amado L.; BERVIAN, Pedro A., DA SILVA, Roberto. Metodologia Científica. Pearson: São Paulo. 6ª ed., 2014.

CLARK, X., DOLLAR, D. and MICO, A. (2004) Port efficiency, maritime transport costs, and bilateral trade. Journal of Development Economics 75(2): 417-450.

COMEXSTAT. MDIC. Disponível em: http://comexstat.mdic.gov.br/pt/geral Acesso em 16 Ago 2018.

DAVID, Pierre; STEWART, Richard. Logística Internacional. Cengage: São Paulo. $2^{\mathrm{a}}$ ed. 2010.

DE SOUZA, G.A., Beresford, A.K.C., and Pettit, S.J., 2003. Liner shipping companies and terminal operators: internationalization or globalization? Maritime Economics and Logistics, 5 (4), 393-412.

DICIO. Dicionário online de português. Disponível em:

https://www.dicio.com.br/expert/. Acesso em 16 de Ago de 2018.

EMBRAPA. Complexo portuário de Itajaí. Disponível em:

$<$ https://www.embrapa.br/macrologistica/exportacao/porto_itajai> Acesso em Outubro 2018.

FAWCETT, S., and D. CLOSS. 1993. "Coordinated Global Manufacturing, the Logistics/Manufacturing Interaction and Firm Performance." Journal of Business Logistics 14 (1): 1-25.

FERRARI, Claudio; PAROLA, Francesco; GATTORNA, Enrico. Measuring the quality of port hinterland accessibility: The Ligurian case. Transport Policy, v. 18, n. 2, p. 382-391, 2011.

FLEURY, P.F.; LAVALLE, C. Avaliação do serviço de distribuição física: a relação entre a indústria de bens de consumo e o comércio atacadista e varejista. In: FLEURY, P.; WANKE, P.; FIGUEIREDO, K. (Orgs.). Logística Empresarial: a perspectiva brasileira. São Paulo: Atlas, 2000. p.76-89.

FOGLIATTI de Sinay, M. C., \& FERNANDES, M. G. (2010). Operational performance of terminals of containers. International Journal of Logistics Systems and Management, 6(2), 190-204.

GOVERNO DE SANTA CATARINA. Santa Catarina amplia exportação de carne bovina. Disponível em : https://www.sc.gov.br/index.php/noticias/temas/agricultura- 
e-pesca/santa-catarina-amplia-exportacao-de-carne-bovina. Acesso em Outubro 2018.

HARDING, A. and JUHEL, M.H., 1997. Port cities and the challenge of global logistics. 6th international conference of cities and ports, November 1997, Association Internationale Villes et Ports, Montevideo, Uruguay.

HEAVER, T.D., 2002. The evolving roles of shipping lines in international logistics. International Journal of Maritime Economics, 4 (3), 210-230.

INVESTESC. Economia diversificada. Disponível em: $<$ http://www.investesc.com/por-que-santa-catarina/economia-diversificada/>. Acesso em Outubro 2018.

JIE, Gao. Conceptualized Discussion on Port Supply Chains: Structure, Characteristics and Evolution Process. Sponsored by Application Basic Projects of Ministry of Communications of China (2007329810060), Science \& Technology Program of Shanghai Maritime University (2008434) and the Research Fund for the Cultivation of PostgraduatesInnovativeAbilityof ShanghaiMaritimeUniversity (YC2008003).2009.

KEEDI, S. Transportes, unitização e Seguros Internacionais de Carga: prática e exercícios. 5 ed. São Paulo, SP: Aduaneiras, 2011.

LEVINSON, M. The Box: How the shipping container made the world economy bigger. New Jersey, USA: Princeton University Press, 2008.

LIU, X.; JIAO, X.; MA, T. Empirical study on port logistics competitiveness based on FCE - AHP. Proceedings of the International Conference on Information Management Proceedings of the International Conference on Information Management, Innovation Management and Industrial Engineering, ICIII 2008, 2008. p.263-269.

LOPEZ, José M. C., GAMA, Marilza. Comércio Exterior Competitivo. São Paulo: Aduaneiras, 2011.

LOPEZ, Raúl Compés; POOLE, Nigel, (1998),"Quality assurance in the maritime port logistics chain: the case of Valencia, Spain", Supply Chain Management: An International Journal, Vol. 3 Iss 1 pp. 33 - 44 Permanent link to this document: http://dx.doi.org/10.1108/13598549810200915.

LIU, Xin Tian, Liming Liu, K. K. Lai \& Shouyang Wang (2013) Analysis and forecasting of port logistics using TEI@I methodology, Transportation Planning and Technology, 36:8, 685-702, DOI: 10.1080/03081060.2013.851506.

LUZ, E. M.; RODRIGUEZ, C. M. T.; FRAZZON, E. M.; ARIAS, J. A. C.. Uma Proposta de Modelo de uma Central de Cargas. Um Estudo Aplicado em um Porto Catarinense. In: ANAIS DO V CONGRESSO INTERNACIONAL DE DESEMPENHO PORTUáRIO, 2018, Florianópolis. Anais eletrônicos... Campinas, GALOÁ, 2018. Disponível em: <https://proceedings.science/cidesport/cidesport-2018/papers/uma- 
proposta-de-modelo-de-uma-central-de-cargas--um-estudo-aplicado-em-um-portocatarinense-> Acesso em: 31 dez. 2018.

MAGALA, M. and SAMMONS, A. (2008) A new approach to port choice modeling. Maritime Economics \& Logistics 10: 9-34.

MARLOW, P.B. and PAIXÃO, A.C., 2003. Measuring lean ports performance. International Journal of Transport Management, 1 (4), 189-202.

MARCONI, Marina D. A.; LAKATOS, Eva M. Metodologia do trabalho científico. São Paulo: Atlas, $8^{a}$ ed.,2017.

MEDEIROS, João B. Redação Científica. A prática de fichamentos, Resumos, Resenhas. São Paulo: Atlas. $11^{a}$ ed. 2009.

MORASH, E.A. and CLINTON, S.R., 1997. The role of transportation capabilities in international supply chain management.Transportation Journal, 36 (3), 5-17.

MSC. Mediterranean Shipping Company. Disponível em:

$<$ https://www.msc.com/gbr/our-services/reefer-cargo/uk-reefer-cargo-

services?lang=pt-br.> Acesso em 16 Ago de 2018.

MUSSA, M. 2003. "Meeting the Challenges of Globalisation." Journal of African Economies, Supplement, AERC Plenary Session 200012 (1): 14-34.

NOTTEBOOM, T.E. and WINKELMANS, W., Structural changes in logistics: how will port authorities face the challenge? Maritime Policy and Management, 28 (1), 7190, 2001.

NOTTEBOOM, T. E.; RODRIGUE, J. Port regionalization: towards a new phase in port development. Maritime Policy \& Management, v. 32, n. 3, p. 297-313, 2005.

OKUBO, Y. Bibliometric Indicators and Analysisof research systems: methods and examples.

PANAYIDES, Ph.M., 2006. Maritime logistics and global supply chains: towards a research agenda. Maritime Economics and Logistics, 8 (2), 3-18.

PAIXÃO, A.C. and MARLOW, P.B., 2003. Fourth generation ports - a question of agility? International Journal of Physical Distribution and Materials Management, 33 (4), 355-376.

PETTIT, S. J. and BERESFORD, A. K. C. (2009). Port development: from gateways to logistics hubs. Maritime Policy \& Management, 36, 253-267.

PIZZOLATO, Nélio D.; SCARVARDA, Luiz F.; PAIVA, Rodrigo. Zonas de influência portuárias-hinterlands: conceituação e metodologias para sua delimitação. Gest. Prod., São Carlos, v. 17, n. 3, p. 553-566, 2010. 
ROBINSON, R., 2002. Ports as elements in value-driven chain systems: the new paradigm. Maritime Policy and Management, 29 (3), 21-40.

ROBINSON, R., 2006. Port-oriented landside logistics in Australian ports: a strategic framework. Maritime Economics and Logistics, 8 (1), 40-59.

ROJAS, Pablo. Introdução à Logística Portuária. E noções de comércio exterior. Bookamn: Porto Alegre. 2014.

SEVERINO, Antônio J. Metodologia do trabalho científico. Editora Cortez: São Paulo. 24ª Edição revista e atualizada. 2016.

SHAO, W.; DU, Y.; and LU, S. Performance evaluation of port supply chain based on fuzzy-matter-element analysis. Journal of Intelligent \& Fuzzy Systems 31 (2016) 2159-2165. DOI:10.3233/JIFS-169055.

SIGNIFICADOS. Significados, conceitos e definições. Disponível em: https://www.significados.com.br/expert/. Acesso em 16 de Ago de 2018.

SLACK, B. and FRÉMONT, A., 2005. Transformation of port terminal operations: from the local to the global. Transport Reviews, 25 (1), 117-130.

SNP. Secretaria Nacional dos Portos. Plano Mestre do Complexo Portuário de Itajaí. Disponível em:<http://www.transportes.gov.br/images/SNP/planejamento_portuario/planos_mes tres/sumario_executivo/se14.pdf. Acesso em outubro 2018.

TIAN, Xin; LIU, Liming; LAI, K. K.; WANG, Shouyang. (2013) Analysis and forecasting of port logistics using TEI@I methodology, Transportation Planning and Technology, 36:8, 685-702, DOI: 10.1080/03081060.2013.851506.

TONGZON, J. and HENG, W., 2005. Port privatization, efficiency and competitiveness: some empirical evidence from container ports (terminals).

Transportation Research A, 39 (5), 405-424.

UNCTAD, 1995. The challenge of integrated transport services. New York: UN.

WANG, T.-F. and CULLINANE, K.P.B., 2006. The efficiency of European container terminals and implications for supply chain management. Maritime Economics and Logistics, 8 (1), 82-99.

WANKE, P. Physical infrastructure and shipment consolidation efficiency drivers in Brazilian ports: Atwo-stagenet work-DEA approach. Journal Transport Policy, $n$. 29 , p. $145-153,2013$.

WINTER, N., KELLOGG, D. L. "How process of operations management view service operations," Production and Operations Management. Baltimore, vol. 8, pp. 339-355, Fall 1999. 
ZOUARI, Z.; KHAYECH, K. Performance evaluation of port logistics: The case of the Sousse port. 2011 4th. International Conference on Logistics, LOGISTIQUA'2011, 2011. p.241-247.

\section{APÊNDICE A - Questionário modelo 1 - Aplicado aos experts dos portos}

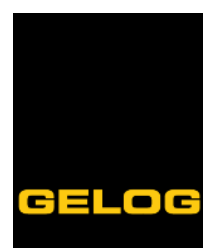

Sou Evandro Moritz Luz, mestrando do Programa de Pós-graduação em Engenharia de Produção da Universidade Federal de Santa Catarina, e membro pesquisador do GELOG (Grupo de Estudos Logísticos). Estou atuando em estudos na área da Cadeia Logístico-Portuária e quero pedir a sua colaboração para uma de minhas pesquisas através das respostas deste questionário. Meu estudo engloba toda a parte da cadeia, e no momento com foco na parte interna do porto. Subdividi em 4 macro etapas principais de atividades que acontecem no ambiente: RECEBIMENTO, ARMAZENAGEM e MOVIMENTAÇÃO, CARREGAMENTO e EMBARQUE. É interessante ressaltar que foco em cargas de contêiner reefer, cargas alimentícias principalmente. Ressaltando a confidencialidade do nome dos entrevistados e das empresas envolvidas. Segue anexado uma ilustração proposta de uma cadeia Logístico-Portuária a fim de ser avaliada e julgada pelos mesmos.

1) Dada a divisão feita das macros etapas principais do porto, recebimento, armazenagem e movimentação, carregamento e embarque, são realmente essas as macro etapas fundamentais do processo? Caso contrário, quais seriam as etapas não mencionadas? 


\section{LEGITIMAÇÃO DO MODELO DA CADEIA}

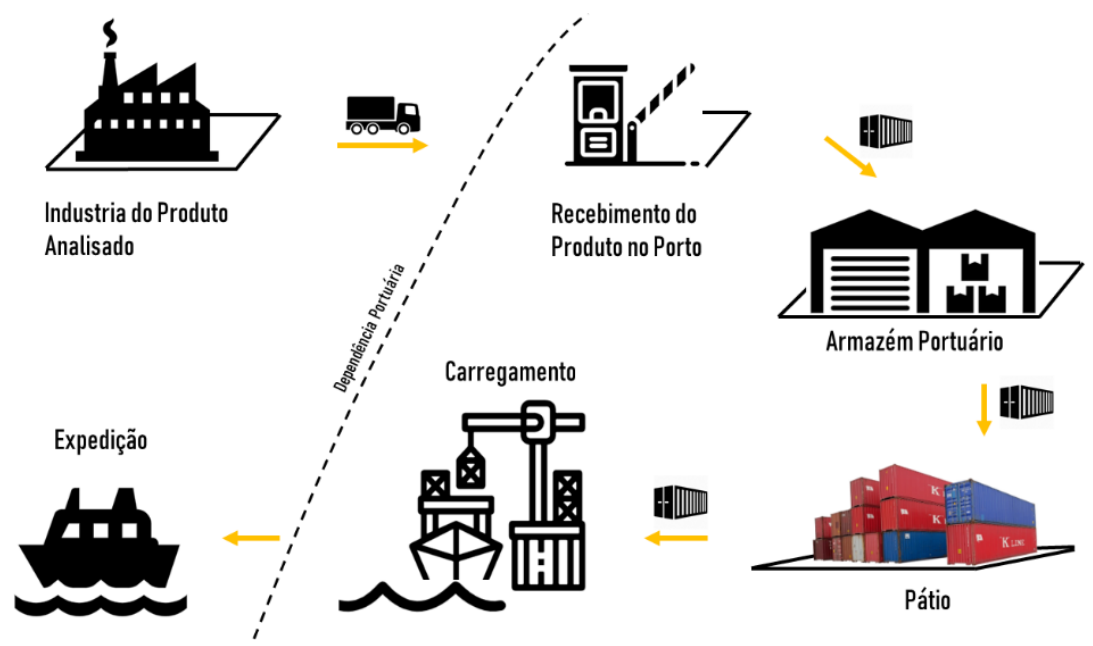

1) A partir da imagem avalie a consistência da cadeia, etapas e fluxos.

\begin{tabular}{|c|c|c|c|c|}
\hline $\begin{array}{c}1-\text { Muito } \\
\text { Baixo }\end{array}$ & 2 - Baixa & 3 - Básica & 4 - Alta & 5 - Muito Alta \\
\hline & & & & \\
\hline
\end{tabular}

2) Deixe aqui suas sugestões para alterações e acréscimo de informações da cadeia 


\section{APÊNDICE B - Questionário modelo 2 - Aplicado aos experts das empresas exportadoras}

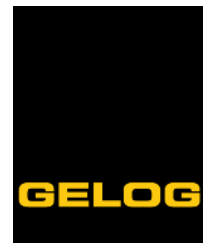

Sou Evandro Moritz Luz, mestrando do Programa de Pós-graduação em Engenharia de Produção da Universidade Federal de Santa Catarina, e membro pesquisador do GELOG (Grupo de Estudos Logísticos). Estou atuando em estudos na área da Cadeia Logístico-Portuária e quero pedir a sua colaboração para uma de minhas pesquisas através das respostas deste questionário.

Meu estudo engloba toda a parte da cadeia portuária. Subdividi em 4 macro etapas principais de atividades que acontecem no porto: RECEBIMENTO, ARMAZENAGEM e MOVIMENTAÇÃO, CARREGAMENTO e EMBARQUE. É interessante ressaltar que foco em cargas de contêiner reefer, cargas alimentícias principalmente. Ressaltando a confidencialidade dos nomes dos entrevistados e das empresas envolvidas. Segue anexado uma ilustração de uma proposta de uma cadeia logístico-Portuária a fim de ser avaliada e julgada pelos mesmos.

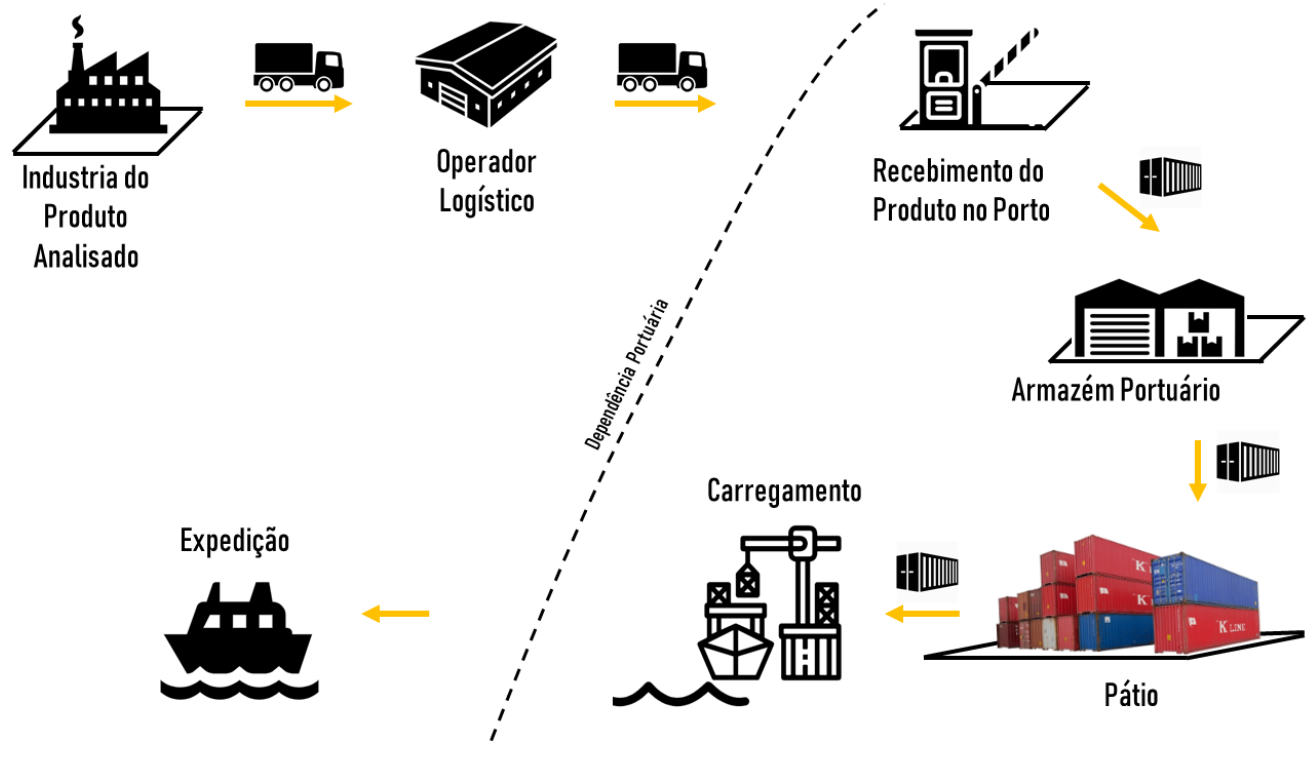

1) Avalie se a imagem é concisa com a realidade de operações:

\begin{tabular}{|c|c|c|c|c|}
\hline $\begin{array}{c}1-\text { Muito } \\
\text { Baixo }\end{array}$ & 2 - Baixa & 3 - Básica & 4 - Alta & 5 - Muito Alta \\
\hline & & & & \\
\hline
\end{tabular}

Deixe suas considerações sobre a cadeia avaliada 


\section{Cadeia e Serviços}

1) Você utiliza de operadores logísticos? Se sim, para qual segmento? (Transporte, armazenagem)? Como a carga é direcionada ao porto? Há agentes intermediários? Explique. 